\title{
The Effect of Nicoumalone on Embryogenesis: A Retrospective Study
}

\author{
Chaitanya Kumar Nelavayi ${ }^{1} \quad$ Kumar Achukatla $\quad$ Bhanu Prakash Badhvel ${ }^{1} \quad$ Sree Veena Gurram ${ }^{1}$ \\ Vanajakshamma Velam ${ }^{3}$ Latha Pujari ${ }^{4}$
}

1Department of Pharmacy Practice, Sree Vidyanikethan College of Pharmacy, Tirupati, Andhra Pradesh, India

2Department of Cardiology, Nizam's Institute of Medical Sciences, Hyderabad

${ }^{3}$ Department of Cardiology, SVIMS, Tirupati, Andhra Pradesh, India

${ }^{4}$ Department of Pharmacology, Sree Vidyanikethan College of

Pharmacy, Tirupati, Andhra Pradesh, India

Indian J Cardiovasc Dis Women-WINCARS 2018;3:189-192

\begin{abstract}
Address for correspondence Kumar Achukatla, Pharm D, Department of Cardiology, Nizam's Institute of Medical Sciences, Punjagutta, 500082 , Hyderabad, Telangana, India (e-mail: achukatlakumar@gmail.com).
\end{abstract}

\begin{abstract}
Keywords

- nicoumalone

- pregnancy

- mechanical valve prostheses

Objective To study the effect of nicoumalone on embryogenesis in women who have undergone mechanical heart valve replacement surgery.

Design It is a retrospective study done at Sri Venkateswara Institute of Medical Sciences (SVIMS), Tirupati.

Results Total 28 pregnancies were reported in 12 women with mechanical heart valve prostheses. Of these, 19 were live births, 9 abortions, and no stillbirths and miscarriages were noted in pregnant women. There were 11 hemorrhagic, 3 neurologic, 2 thromboembolic, and 1 stuck valve complications observed in mothers; and 2 low birth weights, 2 pneumonia, and 1 jaundice observed in the child.

Conclusion There were no abnormalities observed in children whose mothers were taking nicoumalone throughout pregnancy based on echo results and clinical examination.
\end{abstract}

\section{Introduction}

Valvular heart disease (VHD) is one of the major causes of cardiovascular morbidity and mortality, with rheumatic heart disease (RHD) being the most common cause. ${ }^{1}$ The prevalence of VHD is greater in developed countries (2.5\%), where the frequency of RHD is decreased and it is compensated by the increased frequency of degenerative valve disease. ${ }^{2}$ However, RHD is the main cause in developing countries such as India. ${ }^{3}$

Valvular heart diseases can be managed by either drug therapy (e.g., oral anticoagulants [coumarin derivatives], lowmolecular-weight heparin [LMWH], unfractionated heparin [UFH], and low-dose aspirin) or surgical treatment. ${ }^{4}$ Heart valve replacement is the last stage of treatment in these patients. There are two types of prosthetic heart valve replacement (PHVR) currently in use: mechanical and bioprosthetic. Mechanical valves are more commonly used than bioprosthetic valves due to more durability and less risk of reoperation rate.

Women with reproductive age are implanted with mechanical valve prostheses due to its longevity, but they require lifelong anticoagulation therapy. The risk of prosthetic valve thrombosis is higher with mechanical valves compared with bioprosthetic and homograft. During pregnancy, the hormonal changes affect the heart valves as the increase in levels of estrogen hormone leads to the valve thrombus, even on with anticoagulant therapy. ${ }^{5}$ The physiologic changes in pregnancy such as an increase in plasma volume, cardiac output, and hypercoagulability in them due to increased plasma concentration of fibrinogen, factors VII, VIII, and X, and plasminogen activator inhibitor contribute to the increased incidence of thromboembolic (TE) events during pregnancy. Anticoagulant therapy is essential to reduce the TE events throughout pregnancy. ${ }^{6}$ During anticoagulant therapy, pregnant women are monitored with prothrombin time (PT) and international normalized ratio (INR) due to increased risk of TE events with anticoagulants and mechanical valves, so PT-INR monitoring must be done in pregnant women.

Previously the anticoagulant warfarin was recommended in pregnant women after prosthetic heart valve 
replacement. However, it crosses the placenta and produces fetal abnormalities such as congenital heart defects, ventriculomegaly, facial dysmorphism, and growth retardation, etc. ${ }^{6,7}$ To overcome these effects, in the past few years, pregnant women with mechanical prosthesis were recommended with nicoumalone, a vitamin $\mathrm{K}$ antagonist (VKA). It has many advantages such as rapid onset of action, ${ }^{8,9}$ better stability, ${ }^{10,11}$ and no fetal abnormalities. But the major side effect of nicoumalone is bleeding complications. ${ }^{12}$

Previous studies were mainly focused on the influence of anticoagulation regimen in pregnant women with prosthetic heart valves. There has been a little investigation done on maternal and infant outcomes and also the safety of nicoumalone in children. The current study was undertaken to find out the safety of nicoumalone in children.

\section{Methods and Materials}

\section{Study Site}

Department of Cardiology and Cardiothoracic surgery in Sri Venkateswara Institute of Medical Sciences (SVIMS), Tirupati.

\section{Study Period}

Six months (December 2016 to May 2017).

\section{Study Design}

Retrospective study.

\section{Ethical Considerations}

The research project was approved by the institutional ethics committee at SVIMS under IEC number 615.

\section{Methodology}

Female patients aged $\leq 35$ years with a prosthetic heart valve who were taking nicoumalone throughout pregnancy are included and pregnant women who used other drugs that cause fetal anomalies and also pregnant women who switched to heparin therapy are excluded. The demographic, clinical, and surgical information were taken from the case sheets, treatment charts, and recorded in a specifically prepared proforma. The selection of prosthetic valve (mechanical or bio prosthetic) was based on the preoperative discussion between the surgeon, patient, and their family members. The surgeon gives the detailed information regarding the advantages and disadvantages of prosthetic valves such as requirement of anticoagulant therapy after mechanical valve replacement or a possible requirement of reoperation after bioprosthetic valve replacement. The decision of the prosthetic valve selection was entirely left to patients and their family members. ${ }^{13}$ Informed consent was taken from all patients after explaining the nature of the study. During the follow-up visit, the clinical examination and echo were done to the children born to mothers who were taking nicoumalone throughout pregnancy.

The study plan is represented in -Fig. 1 .

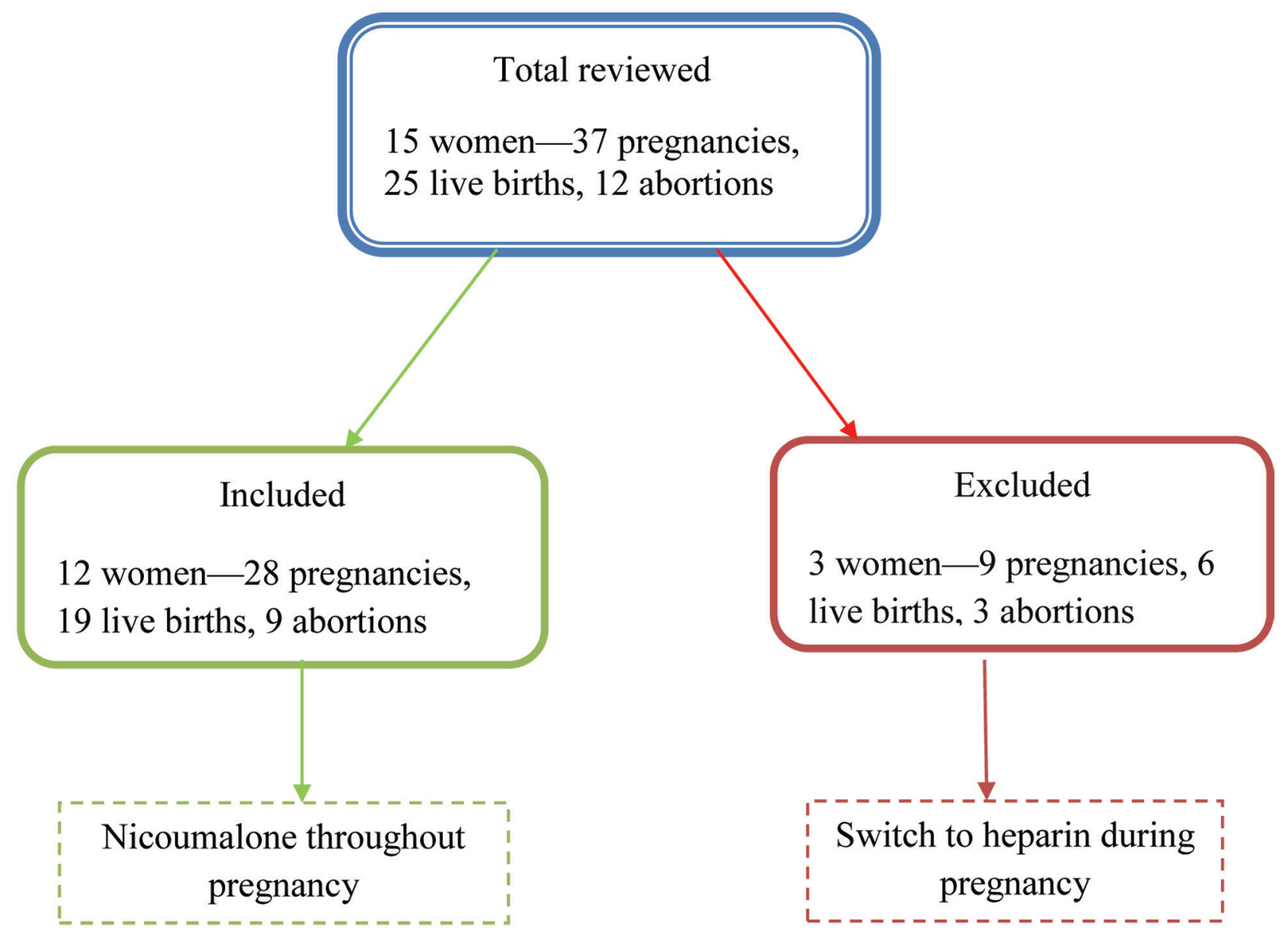

Fig. 1 Plan of study. 


\section{Results}

Twenty-eight pregnancies were reported in 12 women. Of these, 19 live births and 9 abortions were noted and no stillbirths and miscarriages. There were 10 (83.4\%) mitral, 1 (8.3\%) aortic, and 1 (8.3) double-valve replacements done. The mode of delivery of these women is normal (17) and cesarean (4). There were 11 hemorrhagic, 3 neurologic, 2 thromboembolic, and 1 stuck valve complications observed in the mother (-Table 1); and 2 low birth weights, 2 pneumonia, and 1 jaundice observed in the child. There were no congenital or birth defects seen in live births(-Table 2).

\section{Discussion}

Anticoagulation therapy is necessary for the pregnant women with a mechanical heart valve, but the management

Table 1 Maternal outcomes

\begin{tabular}{|c|c|}
\hline Mother characteristics & Results \\
\hline \multicolumn{2}{|l|}{ 1. Valve site } \\
\hline MVR & $10(83.4 \%)$ \\
\hline AVR & $1(8.3 \%)$ \\
\hline DVR & $1(8.3 \%)$ \\
\hline \multicolumn{2}{|l|}{ 2. Delivery } \\
\hline Normal & $9(75 \%)$ \\
\hline Cesarean & $3(25 \%)$ \\
\hline \multicolumn{2}{|c|}{ 3. Nicoumalone dose per week (mg) } \\
\hline $0-10$ & $1(8.3 \%)$ \\
\hline $11-20$ & $8(66.7 \%)$ \\
\hline $21-30$ & $3(25 \%)$ \\
\hline \multicolumn{2}{|l|}{ 4. Prenatal outcomes } \\
\hline Live births & 19 \\
\hline Abortions & 9 \\
\hline Still births & 0 \\
\hline \multicolumn{2}{|l|}{ 5. Complications } \\
\hline Hemorrhagic & 11 \\
\hline Neurologic & 3 \\
\hline Thromboembolic & 2 \\
\hline Stuck valve & 1 \\
\hline
\end{tabular}

Abbreviations: AVR, aortic valve replacement; DVR, double-valve replacement; MVR, mitral valve replacement.

Table 2 Child outcomes

\begin{tabular}{|l|l|}
\hline Child characteristics & Results \\
\hline 1. Sex & 10 \\
\hline Male & 9 \\
\hline Female & \multicolumn{2}{|l|}{} \\
\hline 2. Complications & 2 \\
\hline Low birth weight & 2 \\
\hline Pneumonia & 1 \\
\hline Jaundice &
\end{tabular}

of anticoagulation therapy is a difficult challenge because it should give adequate protection from thrombotic events as well as without causing harm to the unborn child.

As per ACC/AHA (American College of Cardiology/American Heart Association) 2014 guidelines, VKA are required to use to attain the therapeutic INR in the second and third trimesters and initiate UFH intravenously before planned vaginal delivery after discontinuation of VKA. ${ }^{14,15}$ It is recommended that VKA be switched to LMWH or UFH in cesarean delivery at 34 to 36 weeks at around 38 weeks. UFH should be started intravenously at approximately 24 hours prior to labor induction or cesarean and should be stopped once in labor or 6 hours prior to anesthesia administration confirming activated partial thromboplastin time (aPTT) back to baseline. UFH needs to restart at 4 to 6 hours after normal delivery or 6 to 12 hours after cesarean delivery with $500 \mathrm{IU} / \mathrm{h}$ and increase over 24 to 48 hours to target aPTT. VKA should be restarted on first day of postpartum (uncomplicated vaginal delivery) or second to third day if cesarean or bleeding complications occur. ${ }^{16}$ As per D'Souza et al, the use of UFH throughout pregnancy is not supported. ${ }^{17}$

In our study, patients who took nicoumalone throughout the pregnancy were included and patients who took anticoagulant based on the guideline were excluded. In this study, 19 live births and 9 abortions were noted and there were no stillbirths and miscarriages. Abortions may occur due to consanguinity marriages or TE events. The study conducted by Tounsi et al confirmed that there were 1 abortion, 33 live births, 5 stillbirths, and 1 maternal death. ${ }^{18}$

The complications observed in the mother are bleeding, stroke, seizure, and stuck valve. These complications are more in number in mitral valve replacements. A study conducted by Ahamad confirmed that few patients who were taking acenocoumarol had developed central nervous system events and features of peripheralembolization. ${ }^{19}$ The postprocedural symptoms such as a cough, chest pain, palpitations, etc. were observed. The complications observed in the child are low birth weight, pneumonia, and jaundice. Apgar score is a method used to assess a neonate after birth in response to resuscitation. The factors such as color, heart rate, reflexes, muscle tone, and respiration were assessed. The score is recorded at 1 and 5 minutes after birth. ${ }^{20}$

\section{Conclusion}

In this study, there were no congenital, physical, or neurologic abnormalities seen in children whose mothers were taking nicoumalone throughout pregnancy with prosthetic heart valves. These are assessed based on echo results and clinical examination periodically done by the physician. The low birth weight, jaundice, and pneumonia in children were not associated with nicoumalone therapy. Therefore, we conclude that the nicoumalone is safe in pregnant women with the mechanical prosthetic valve.

\section{Limitations}

- Sample size is small.

- It is a single centered trail. 


\section{References}

1 Carapetis JR. Rheumatic heart disease in developing countries. N Engl J Med 2007;357(5):439-441

2 Vahanian A, Iung B, Himbert D, Nataf P. Changing demographics of valvular heart disease and impact on surgical and transcatheter valve therapies. Int J Cardiovasc Imaging 2011;27(8):1115-1122

3 Iung B, Vahanian A. Epidemiology of acquired valvular heart disease. Can J Cardiol 2014;30(9):962-970

4 Chan WS, Anand S, Ginsberg JS. Anticoagulation of pregnant women with mechanical heart valves: a systematic review of the literature. Arch Intern Med 2000;160(2):191-194

5 Pieper PG. Expected and unexpected cardiac problems during pregnancy. Neth Heart J 2008;16(12):403-405

6 Lindblom D, Lindblom U, Qvist J, Lundström H. Long-term relative survival rates after heart valve replacement. J Am Coll Cardiol 1990;15(3):566-573

7 Hall JG, Pauli RM, Wilson KM. Maternal and fetal sequelae of anticoagulation during pregnancy. Am J Med 1980;68(1):122-140

8 Neill EC, Moon RY, Vander Veer JB. Clinical evaluation of a new oral anticoagulant Sintrom. Circulation 1957;15(5):713-720

9 Rullo FR, Bartels CC, Evans JA. Clinical evaluation of acenocoumarol (Sintrom), an anticoagulant of intermediate range. J Am Med Assoc 1958;168(6):734-737

10 Kulo A, Kusturica J, Kapic E, et al. Better stability of acenocoumarol compared to warfarin treatment in one-year observational, clinical study in patients with nonvalvular AF. Med GlasLjekkomoreZenicko-dobojkantona 2011;8:9-14

11 Lengyel M, SPORTIF-III Altanulmány, Vizsgálói. Warfarin or acenocoumarol is better in the anticoagulant treatment of chronic AF? [in Hungarian]. Orv Hetil 2004;145:2619-2621
12 Trailokya A, Hiremath JS, Sawhney J, et al. Acenocoumarol: a review of anticoagulant efficacy and safety. J Assoc Physicians India 2016;64(2):88-93

13 Kulik A, Bédard P, Lam BK, et al. Mechanical versus bioprosthetic valve replacement in middle-aged patients. Eur J Cardiothorac Surg 2006;30(3):485-491

14 Nishimura RA, Otto CM, Bonow RO, et al. 2017 AHA/ACC focused update of the 2014 AHA/ACC guideline for the management of patients with valvular heart disease. J Am Coll Cardiol 2017;70(2):252-289

15 Nishimura RA, Otto CM, Bonow RO, et al. 2014 AHA/ACC guideline for the management of patients with valvular heart disease a report of the American College of Cardiology/ American Heart Association task force on practice guidelines. Circulation 2014;129(23):2440-2492

16 McLintock C, McCowan LME, North RA. Maternal complications and pregnancy outcome in women with mechanical prosthetic heart valves treated with enoxaparin. BJOG 2009;116(12):1585-1592

17 D'Souza R, Ostro J, Shah PS, et al. Anticoagulation for pregnant women with mechanical heart valves: a systematic review and meta-analysis. Eur Heart J 2017;38(19):1509-1516

18 Tounsi A, Abid D, Louati D, et al. Anticoagulation in pregnant women with mechanical heart valve prostheses: 25-year experience at a tertiary care hospital in a developing country. World J Cardiovasc Dis 2014;4(6):287-293

19 Ahamad Mir I. Role of acenocoumarol in prosthetic heart valves. JIMD 2015;2(3):180-185

20 Simon LV, Bragg BN. APGAR Score. StatPearls, November 29, 2017 